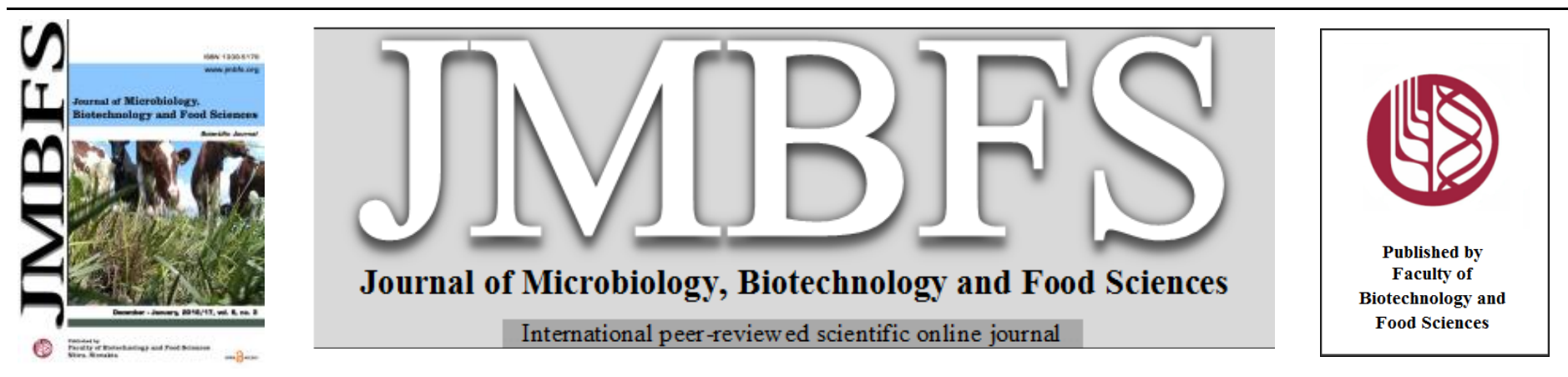

\title{
THE ANTIMICROBIAL AND ANTIOXIDANT POTENCIES OF SATUREJA KHUZISTANICA ESSENTIAL OIL FOR PRESERVING OF VEGETABLE OILS
}

\author{
Behnaz Bahrami ${ }^{1}$, Mohaddese Mahboubi ${ }^{2 *}$, Reza Yari ${ }^{1}$, Mehdi Mehran $^{3}$
}

\author{
Address(es): \\ ${ }^{1}$ Biology Department, Faculty of Sciences, Boroujerd Branch, Islamic Azad University, Boroujerd, Iran. \\ ${ }^{2}$ Microbiology Department, Medicinal Plant Research Center of Barij, 87135-1178 Kashan, Iran. \\ ${ }^{3}$ Phytochemistry Department, Medicinal Plants Research Center of Barij, 87135-1178 Kashan, Iran.
}

*Corresponding author: mahboubi1357@yahoo.com ; mahboubi@barijessence.com

doi: $10.15414 /$ jmbfs.2016/17.6.3.979-982

\section{ARTICLE INFO}

Received 16. 2. 2016

Revised 26. 10. 2016

Accepted 1.11. 2016

Published 1. 12. 2016

Regular article

open 2 access

\begin{abstract}
In recent years, the use of natural preservatives for protection of vegetable oils against microbial and chemical deterioration is one of the interesting issues. The purpose of this study was to evaluate the preservative activity of Satureja khuzistanica essential oil (SKEO) against microbial and chemical deterioration in sesame and flaxseed vegetable oils. Chemical composition of SKEO, chemical profiles, antioxidant and preservative potencies of inoculated vegetable oils with different concentration of SKEO were determined. Carvacrol was the main component of SKEO. The chemical profile of vegetable oils in presence of SKEO had no changes. Sesame and flaxseed vegetable oils had the $\mathrm{IC}_{50}$ equal to 26 and $22 \mu \mathrm{g} / \mathrm{ml}$, respectively. Inoculation the SKEO (1\%v/v) in vegetable oils decreased the $\mathrm{IC}_{50}$ for vegetable oils. SKEO showed promised antimicrobial activity against food microorganisms. Inoculation the SKEO $(0.75 \% \mathrm{v} / \mathrm{v})$ in sesame oil inhibited completely the bacteria and fungi after 14 days. Flaxseed oil inoculated with SKEO (1\% v/v and lower concentrations) decreased the bacteria and fungi populations after 28 days. Therefore, the use of SKEO as natural preservative can protect vegetable oils from deterioration; also it gives the vegetable oils the other pharmacological effects such as anti-inflammatory and analgesic effects with applications in different industries.
\end{abstract}

Keywords: Preservative, Essential oil, Satureja khuzistanica, Antioxidant, Vegetable oil

\section{INTRODUCTION}

Inadequate drying process of oilseeds or poor situation in extracting the vegetable oils from oilseeds usually leads to microbial contamination in final products (Okpokwasili and Molokwu, 1996). Microbial contaminations can make considerable changes in vegetable oils and finally affect on quality of these vegetable oils.

In contrast, the difference in intrinsic properties of vegetable oils can change the microbial load of vegetable oils. The fatty acid profile, phenolic compounds, tocopherol and sterol contents of vegetable oils have critical role in their intrinsic properties (Gromadzka and Wardencki, 2011).

In addition to microbial contaminations in vegetable oils, the oxidants can affect on their shelf life (Aluyor and Ori-Jesu, 2008). Benzoic acid, nitrites, sulfites as antimicrobial agents and butylated hydroxyltoluene (BHT), butylated hydroxyanisole (BHA), tocopherols and ascorbic acid as antioxidants are used for prevention the vegetable oils from spoilage. The application of chemical antioxidants and preservatives are associated with major health hazardous problems and toxicity (Parke and Lewis, 1992). Furthermore, replacement the chemical and synthetic ones with natural agents in vegetable oils has great importance for many consumers of food, pharmaceutical and cosmetic industries in different parts of the worlds.

In these years, the use of essential oils as natural preservatives and antioxidants has increased as a new approach to overcome on these adverse effects (Davidson and Taylor., 2007; Lambert et al., 2001; Mahboubi et al., 2014; SmithPalmer et al., 2001).

Satureja khuzistanica essential oil (Lamiaceae family) has been known for its antiseptic effects in traditional medicines. The antimicrobial activities of $S$. khuzistanica essential oil have been determined against a large number of bacteria and fungi in vitro conditions (Akbari-Shahabi et al., 2014; SadeghiNejad et al., 2010; Zarrin et al., 2010). Other biological effects of $S$. khuzistanica such as anti-inflammatory (Ghazanfari et al., 2006), antinociceptive and analgesic (Saberi et al., 2013) activities have been confirmed. Therefore, inoculation of $S$. khuzistanica essential oil into vegetable oils may be proposed it as suitable candidate for different industries especially in aromatherapy related therapies.

So, the aim of this study was to evaluate the preservative and antioxidant potencies of S. khuzistanica essential oil in sesame and flaxseed oils. These vegetable oils are two popular vegetable oils in different industries. Due to a positive relation between the chemical composition of essential oil and biological activities, we analyzed the chemical composition of $S$. khuzistanica essential oil and fatty acid profiles of vegetable oils in presence of this essential oil as natural preservative.

\section{MATERIAL AND METHODS}

S. khuzistanica essential oil and analysis of its chemical composition by Gas Chromatography (GC) and Gas chromatography-mass spectrometry (GCMS)

Satureja khuzistanica essential oil with pale yellow color had been dedicated by Barij Essence Pharmaceutical Company of Iran. The chemical composition of essential oil were conducted on coupled Agilent technology (HP) 6890 with capillary column of HP-1MS $(30 \mathrm{~m} \times 0.25 \mathrm{~mm}$, film thickness $0.25 \mu \mathrm{m})$ and Agilent technology (HP) 6890 with 5973 network mass selective detector system using GC and GC-MS apparatuses. The oven temperature program was initiated at $40{ }^{\circ} \mathrm{C}$, held for $1 \mathrm{~min}$ then raised up to $230{ }^{\circ} \mathrm{C}$ at a rate of $3{ }^{\circ} \mathrm{C} / \mathrm{min}$, held for $10 \mathrm{~min}$. Helium as the carrier gas at a flow rate of $1.0 \mathrm{ml} / \mathrm{min}$ with a split ratio equal to $1 / 50$ injector were used. The detector and injector temperatures were 250 and $230{ }^{\circ} \mathrm{C}$, respectively. Components of essential oil were identified by comparison with Retention indices (RI) relative to homologous series of nalkanes (injected in conditions equal to samples ones) and by computer search using libraries of Wiley 275.L and Wiley 7n.1, as well as comparison of the fragmentation pattern of the mass spectra with data published in the literature (Adams, 2001). 
The microbial strains were including: Staphylococcus aureus ATCC 6538, Escherichia coli ATCC 8739, Pseudomonas aeruginosa ATCC 9027, Candida albicans ATCC 10231, Aspergillus niger ATCC 16404. The inhibition zones (IZ) diameters, the minimal inhibitory concentration (MIC) and minimal lethal concentration (MLC) values of essential oil were evaluated by disc diffusion and micro broth dilution assay as it reported elsewhere (Mahboubi et al., 2014).

Table 1 GC and GC-MS analysis of Satureja khuzistanica oil

\begin{tabular}{lcc}
\hline compound & RI & \% \\
\hline$\alpha$-terpinene & 929 & 0.2 \\
p-cymene & 938 & 0.5 \\
$\beta$-phellandrene & 941 & 0.1 \\
$\gamma$-terpinene & 971 & 0.4 \\
$\alpha$-terpinolene & 999 & 0.1 \\
linalool & 1013 & 0.1 \\
carvacrol methyl ether & 1142 & 0.1 \\
thymol & 1200 & 1.0 \\
Carvacrol & 1257 & $\mathbf{8 4}$ \\
Eugenol & 1295 & 0.2 \\
carvacryl acetate & 1303 & 0.02 \\
trans-caryophyllene & 1327 & 0.4 \\
$\alpha$-bergamotene & 1336 & 0.1 \\
neryl acetone & 1350 & 0.1 \\
$\beta$-Bisabolene & 1387 & 2.7 \\
\hline
\end{tabular}

RI-retention index

\section{Vegetable oils}

Two samples of vegetable oils (sesame oil, flaxseed oil) were used. Vegetable oils were extracted from the seeds of Sesamum indicum (sesame oil) and Linum usitatitissimum (flaxseed) by cold press procedures in Glkaran Company, Kashan, Iran. The chemical properties of vegetable oils were determined as below. $0.2 \mathrm{ml}$ of $1 \mathrm{M}$ potassium hydroxide and $10 \mathrm{ml}$ of methanol were added to $300 \mathrm{mg}$ of each vegetable oil, then, it was refluxed for $10 \mathrm{~min}$ at $90{ }^{\circ} \mathrm{C}$. After cooling of this solution, the components of vegetable oils were extracted by hexane. $1 \mu \mathrm{l}$ of extracted components was injected to GC-CP3800 (Varian) with a column of CP-Wax $52 \mathrm{CB}(50 \mathrm{~m} \times 0.32 \mathrm{~mm}$, film thickness $0.2 \mu \mathrm{m})$. Nitrogen was used as carrier gas (pressure $7 \mathrm{psi}$, flow rate $1.0 \mathrm{ml} / \mathrm{min}$ ). The temperatures of detector and injector were $250{ }^{\circ} \mathrm{C}$ with split ratio of 10 . The oven temperature program was initiated at $170{ }^{\circ} \mathrm{C}$, held for $10 \mathrm{~min}$, and then raised up to $250{ }^{\circ} \mathrm{C}$ with a rate of $3{ }^{\circ} \mathrm{C} / \mathrm{min}$. After that, it was held for $30 \mathrm{~min}$ at $250{ }^{\circ} \mathrm{C}$.

Vegetable oils were inoculated by different concentrations of $S$. Khuzestanica essential oil $(0.25,0.5,0.75$, and $1 \% \mathrm{v} / \mathrm{v})$. Vegetable oils alone were used as negative controls. Carvacrol as $S$. Khuzestanica essential oil indicator was detected in inoculated vegetable oil.

For this purpose, $1.5 \mathrm{~g}$ of each vegetable oil was mixed with $4.5 \mathrm{~g}$ ethanol $\left(90^{\circ} \mathrm{C}\right)$ and $0.5 \mathrm{ml}$ of hexanol $(10 \mu \mathrm{g} / \mathrm{ml})$. The mixture was put in water bath $\left(60^{\circ} \mathrm{C}\right)$ for $5 \mathrm{~min}$ and then was put in cold water bath $\left(4^{\circ} \mathrm{C}\right)$ for $10 \mathrm{~min}$. Then, the mixture was centrifuged. $1 \mu \mathrm{l}$ of supernatant was injected to GC-Sil 8CB (Varian) with column: CP-Wax52CB $(60 \mathrm{~m} \times 0.32 \mathrm{~mm}$, film thickness $0.45 \mu \mathrm{m})$, nitrogen was used as the carrier gas (pressure $7 \mathrm{psi}$, flow rate of $1.0 \mathrm{ml} / \mathrm{min}$, split ratio of 10 ). The temperatures of injector and detector were 230 and $250{ }^{\circ} \mathrm{C}$, respectively. The oven temperature program was initiated at $50{ }^{\circ} \mathrm{C}$, held for $10 \mathrm{~min}$, then it was raised up to $230{ }^{\circ} \mathrm{C}$ at a rate of $3{ }^{\circ} \mathrm{C} / \mathrm{min}$ and then was held for $70 \mathrm{~min}$ (Pharmacopoeia, 2015a, b).

Table 2 Chemical profiles of vegetable oils and inoculated S. khuzistanica essential oil

\begin{tabular}{|c|c|c|c|c|c|c|c|}
\hline \multirow{2}{*}{ Sample } & \multirow{2}{*}{$\begin{array}{c}\text { IC }_{\mathbf{5 0}} \\
\mu \mathrm{g}\end{array}$} & \multirow{2}{*}{$\begin{array}{c}\text { Essential oil } \\
\text { carvacrol } \\
\end{array}$} & \multicolumn{5}{|c|}{ Vegetable oil (w/w \%) } \\
\hline & & & Palmetic acid & Estearic acid & Oleic acid & Linoleic acid & $\alpha$ - linoleic acid \\
\hline$S$ & 26 & 0.00 & 9.4 & 5.6 & 44.1 & 38.7 & 0.4 \\
\hline SS $(0.25 \%)$ & 21 & 0.21 & 9.4 & 5.6 & 44.1 & 38.7 & 0.4 \\
\hline SS $(0.5 \%)$ & 17 & 0.42 & 9.4 & 5.6 & 44.1 & 38.7 & 0.4 \\
\hline SS $(0.75 \%)$ & 14 & 0.58 & 9.4 & 5.6 & 44.1 & 38.7 & 0.4 \\
\hline SS $(1 \%)$ & 12 & 0.77 & 9.4 & 5.6 & 44.1 & 38.7 & 0.4 \\
\hline $\mathrm{F}$ & 22 & 0.02 & 5.5 & 5.1 & 19.7 & 13.5 & 54.9 \\
\hline FS $(0.25 \%)$ & 14 & 0.20 & 5.5 & 5.1 & 19.7 & 13.5 & 54.9 \\
\hline FS $(0.5 \%)$ & 13 & 0.36 & 5.5 & 5.1 & 19.7 & 13.5 & 54.9 \\
\hline FS $(0.75 \%)$ & 10 & 0.56 & 5.5 & 5.1 & 19.7 & 13.5 & 54.9 \\
\hline FS $(1 \%)$ & 7 & 0.7 & 5.5 & 5.1 & 19.7 & 13.5 & 54.9 \\
\hline
\end{tabular}

SS- Sesame oil+S.khuzestanica oil, FS- Flaxseed oil+ S.khuzestanica oil

Table 3 The antimicrobial activity of Satureja khuzistanica Essential Oil

\begin{tabular}{lccc}
\hline & Disc diffusion $(\mathbf{m m})$ & \multicolumn{2}{c}{ Broth dilution $(\boldsymbol{\mu g} / \mathbf{m l})$} \\
\hline S. aureus & $\mathbf{0 . 5} \boldsymbol{\mu l}$ & MIC & MLC \\
E. coli & $18.4 \pm 0.12$ & 85 & 170 \\
$P$. aeruginosa & $13.8 \pm 0.33$ & 170 & 170 \\
C. albicans & $11.5 \pm 0.1$ & 340 & 340 \\
A. niger & $23.4 \pm 0.19$ & 43 & 43 \\
\hline
\end{tabular}

$\mathrm{MIC}=$ Minimal Inhibitory Concentration; MLC $=$ Minimal Lethal Concentration

\section{Evaluation the preservative efficacy of $S$. khuzistanica essential oil in} vegetable oils

The preservative efficacy of $S$. khuzistanica essential oil in vegetable oils was evaluated by evaluating the antimicrobial effectiveness testing. Inoculated vegetable oils and negative controls were contaminated with predetermined number of microorganisms that mentioned above $\left(10^{5}-10^{6} \mathrm{CFU} / \mathrm{ml}\right)$. At time intervals $0,7,14,21,28$ days, the $\mathrm{CFU} / \mathrm{ml}$ of microorganisms were determined by inserting the aliquots of inoculated vegetable oils into neutralizing broth media at room temperature, then they serially were diluted and were cultured on specified media cultures. The log $\mathrm{CFU} / \mathrm{ml}$ of each microorganism for each sample were calculated and the results were reported (Sutton and Porter, 2002).

Evaluation the antioxidant activity of $S$. khuzistanica essential oil in vegetable oils

Radical scavenging potency of vegetable oils containing different concentrations of $S$. khuzistanica essential oil $(0,0.25,0.5,0.75$ and $1 \% \mathrm{w} / \mathrm{w})$ were determined by free radicals of 1,1-diphenyl-2-picrylhydrazyl (DPPH). Briefly, $40 \mu \mathrm{l}$ of serial diluted different samples of vegetable oils in methanol was mixed with DPPH. After $70 \mathrm{~min}$ incubation period at room temperature, the absorbance of solutions was read against a blank at $517 \mathrm{~nm}$. Inhibition percent of free radicals was calculated and reported. Vegetable oils were used as controls. All experiments were performed in triplicates (Mahboubi et al., 2013).

Table 4 The preservative potency of Satureja khuzistanica Essential Oil against pathogens in vegetable oils

\begin{tabular}{|c|c|c|c|c|c|c|c|c|c|c|c|c|c|c|c|c|c|c|c|c|c|c|c|c|c|}
\hline \multirow{2}{*}{$\begin{array}{l}\text { Sample } \\
\text { Day }\end{array}$} & \multicolumn{5}{|c|}{ S. aureus } & \multicolumn{5}{|c|}{ E. coli } & \multicolumn{5}{|c|}{ P. aeruginosa } & \multicolumn{5}{|c|}{ C. albicans } & \multicolumn{5}{|c|}{ A. niger } \\
\hline & $\mathbf{0}$ & 7 & 14 & 21 & 28 & $\mathbf{0}$ & 7 & 14 & 21 & 28 & $\mathbf{0}$ & 7 & 14 & 21 & 28 & $\mathbf{0}$ & 7 & 14 & 21 & 28 & $\mathbf{0}$ & 7 & 14 & 21 & 28 \\
\hline $\mathrm{S}$ & 6.3 & 0 & 0 & 0 & 0 & 5.9 & 6.6 & 6.7 & 6.8 & 6.8 & 6.2 & 6.2 & 6.8 & 6.8 & 6.4 & 4.7 & 4.7 & 4.8 & 4.8 & 4.8 & 3.4 & 2.4 & 2.3 & 2.3 & 2.3 \\
\hline SS $(0.25 \%)$ & 6.3 & 0 & 0 & 0 & 0 & 5.9 & 6.5 & 6.7 & 6.8 & 6.8 & 6.2 & 5.9 & 5.9 & 5.9 & 5.3 & 4.7 & 4.5 & 4.1 & 3.9 & 2.4 & 3.4 & 2.4 & 2 & 2 & 1.2 \\
\hline SS $(0.5 \%)$ & 6.3 & 0 & 0 & 0 & 0 & 5.7 & 6.5 & 6.7 & 6.7 & 6.8 & 6.2 & 5.6 & 5.6 & 5.4 & 5.2 & 4.7 & 4.4 & 4 & 3.8 & 3.6 & 3.3 & 1.8 & 0 & 0 & 0 \\
\hline SS $(0.75 \%)$ & 6.3 & 0 & 0 & 0 & 0 & 5.9 & 0 & 0 & 0 & 0 & 6.2 & 2.1 & 0 & 0 & 0 & 4.7 & 3.3 & 1.1 & 0 & 0 & 3.3 & 1.6 & 0.8 & 0 & 0 \\
\hline SS (1\%) & 6.3 & 0 & 0 & 0 & 0 & 5.9 & 0 & 0 & 0 & 0 & 6.3 & 1.0 & 0 & 0 & 0 & 4.7 & 2.1 & 0.7 & 0 & 0 & 3.4 & 1.1 & 0.6 & 0 & 0 \\
\hline $\mathrm{F}$ & 6.9 & 4.7 & 0 & 0 & 0 & 6.9 & 6.2 & 5.9 & 5.7 & 5.6 & 6.2 & 7.9 & 8.8 & 8.6 & 8.6 & 4.7 & 3.9 & 3.8 & 3.7 & 3.7 & 3.6 & 2.6 & 2.5 & 2.4 & 2.4 \\
\hline FS $(0.25 \%)$ & 6.8 & 4.3 & 0 & 0 & 0 & 6.9 & 5.7 & 5.6 & 5.6 & 5.2 & 6.2 & 7.7 & 8.7 & 8.6 & 8.4 & 4.7 & 3.8 & 3.7 & 3.6 & 3.5 & 3.6 & 2.3 & 2.4 & 2.4 & 2.2 \\
\hline FS $(0.5 \%)$ & 6.7 & 4.1 & 0 & 0 & 0 & 6.7 & 5.4 & 5.2 & 5.1 & 4.8 & 6.1 & 7.7 & 8.2 & 7.9 & 7.6 & 4.7 & 3.6 & 3.5 & 3.4 & 3.2 & 3.6 & 2.3 & 2.3 & 2.3 & 2.0 \\
\hline FS $(0.75 \%)$ & 6.3 & 3.8 & 0 & 0 & 0 & 5.9 & 0 & 0 & 0 & 0 & 6.2 & 4.1 & 2.8 & 2.6 & 2.4 & 4.7 & 4.7 & 3.8 & 2.8 & 1.4 & 3.4 & 2.4 & 2.3 & 2.3 & 2.1 \\
\hline FS $(1 \%)$ & 6.3 & 2.8 & 0 & 0 & 0 & 5.9 & 0 & 0 & 0 & 0 & 6.2 & 3.9 & 1.8 & 1.8 & 1.8 & 4.7 & 4.5 & 3.2 & 2.1 & 1.6 & 3.4 & 2.4 & 2 & 2 & 1 \\
\hline
\end{tabular}




\section{RESULTS AND DISCUSSION}

\section{Chemical composition of $S$. khuzistanica essential oil}

Thirty five different components were identified in S. khuzistanica oil representing $93.2 \%$ of total essential oil composition. Carvacrol (84\%), $\beta$ bisabolene $(2.7 \%)$, thymol $(1 \%)$ and p-cymene $(0.5 \%)$ were the main components of S. khuzistanica essential oil (Tab 1).

The effects of $S$. khuzistanica essential oil on chemical profile of vegetable oils

Oleic acid $(44.1 \%)$, linoleic acid (38.7\%), palmitic acid $(9.5 \%)$ and stearic acid $(5.6 \%)$ were the major fatty acids of sesame oil while $\alpha$ - linoleic acid $(54.9 \%)$ oleic acid (19.7\%), linoleic acid (13.5\%), palmitic acid $(5.5 \%)$ and stearic acid $(5.1 \%)$ were the main fatty acids of flaxseed oil (Tab 2 ).

Inoculation the $S$. khuzistanica essential oil in vegetable oils had no effect on chemical profiles of vegetable oils as the Table 2 has been shown. In inoculated vegetable oils with essential oil, the amounts of carvacrol were related to the amounts of carvacrol in inoculated essential oil into vegetable oils.

The effects of $S$. khuzistanica essential oil on antioxidant activity of vegetable oils

The antioxidant evaluation of vegetable oils by DPPH assay showed that sesame oil had $\mathrm{IC}_{50}$ equal to $26 \mu \mathrm{g} / \mathrm{ml}$ and this $\mathrm{IC}_{50}$ was higher than the $\mathrm{IC}_{50}$ for flaxseed oil $(22 \mu \mathrm{g} / \mathrm{ml})$. Inoculation of $S$. khuzistanica essential oil in sesame and flaxseed oils increased the antioxidant potencies of inoculated vegetable oils by reduction in $\mathrm{IC}_{50}$ of vegetable oils, dose dependently (Figure 1, Tab 2). Inoculation the $S$ khuzistanica essential oil $(1 \% \mathrm{v} / \mathrm{v})$ into vegetable oils decreased the $\mathrm{IC}_{50}$ of sesame and flaxseed oils from $26,22 \mu \mathrm{g} / \mathrm{ml}$ to 12 and $7 \mu \mathrm{g} / \mathrm{ml}$, respectively.

\section{Antimicrobial activity of $S$. khuzistanica oil against microorganisms}

The antimicrobial evaluation of $S$. khuzistanica essential oil against tested microorganisms showed that, in disc diffusion method, the most sensitive microorganism was A. niger $(27.3 \mathrm{~mm})$, followed by C. albicans $(23.4 \mathrm{~mm})$, and $S$. aureus $(18.4 \mathrm{~mm})$, respectively. E. coli and $P$. aeruginosa showed the lower inhibition zone diameters than the others (lower than $15 \mathrm{~mm}$ ).

Antimicrobial evaluations of S. khuzistanica essential oils by micro broth dilution assays exhibited the microorganisms had different behavior in broth media in comparison with solid media. C. albicans with MIC and MBC values of $43 \mu \mathrm{g} / \mathrm{m}$ exhibited more sensitivity to $S$. khuzistanica oil, followed by $S$. aureus (MIC $\mathrm{MLC}=85,170 \mu \mathrm{g} / \mathrm{ml})$. A. niger and $E$. coli had the same sensitivity to $S$ khuzistanica oil. $P$. aruginosa was the less sensitive microorganisms to $S$. khuzistanica oil (MIC, MLC $=340 \mu \mathrm{g} / \mathrm{ml}$ ) (Tab 3).

\section{The preservative potency of $S$. khuzistanica essential oil in vegetable oils}

Sesame and flaxseed oils alone inhibited the growth of $S$. aureus, therefore, inoculation of $S$. khuzistanica essential oil in vegetable oils for inhibition the growth of $S$. aureus was meaningless. The $\log \mathrm{CFU} / \mathrm{ml}$ of other bacteria such as $E$. coli and $P$. aeruginosa in vegetable oils did not inhibited by vegetable oils after 28 days. The $\log \mathrm{CFU} / \mathrm{ml}$ of $P$. aeruginosa particularly increased. Inoculating the essential oil $(0.25 \%$ and $0.5 \% \mathrm{v} / \mathrm{v})$ into vegetable oils did not exhibit any preservative effects against bacteria and molds. Sesame oil with $S$ khuzistanica essential oil at concentration of $0.75 \%$ and $1 \%(\mathrm{v} / \mathrm{v})$ completely inhibited the growth of tested microorganisms. Flaxseed oil also inhibited the growth of $E$. coli after 7 days in presence of $0.75 \%(\mathrm{v} / \mathrm{v})$ of $S$. khuzistanica essential oil but the $\log \mathrm{CFU} / \mathrm{ml}$ of $P$. aeruginosa, $C$. albicans and $A$. niger decreased to $2.4,1.4$ and 2.1 after 28 days in inoculated vegetable oil with $S$ khuzistanica essential oil $(0.75 \% \mathrm{v} / \mathrm{v})$. P. aeruginosa was the most resistant microorganisms to inoculated vegetable oils (Tab 4).

As the results are shown, carvacrol was the main components of $S$. khuzistanica essential oil according to the results of other investigators (Saidi, 2014; Siavash Saei-Dehkordi et al., 2012). Furthermore, the antimicrobial activity of $S$ khuzistanica essential oil (Akbari-Shahabi et al., 2014; Siavash Saei-Dehkordi et al., 2012), carvacrol (Cacciatore et al., 2015) and the mechanism of action for carvacrol (Ait-Ouazzou et al., 2013; Chueca et al., 2014) have been confirmed. Also, the antioxidant activity of $S$. khuzistanica essential oil has been reported (Ahmadvand, 2014). Although, there are many investigations on biological activities of $S$. khuzistanica essential oil but to now, there is no study that evaluates the preservative and antioxidant potency of $S$. khuzistanica essential oil in valuable vegetable oils with therapeutic potencies. Nowadays, the use of natural products among the consumers has increased and natural products have good features in different part of the World. Therefore, finding the natura preservatives with other pharmacological potency such as anti-inflammatory and analgesic effects (Esmaeili-Mahani $\boldsymbol{e t}$ al., 2015) can enhance the therapeutic potencies of vegetable oils, meanwhile it can protect vegetable oils against deterioration. S. khuzistanica essential oil by preservative and antioxidant potency protects sesame and flaxseed oils from deterioration and also enhances the therapeutic potency of these oils.
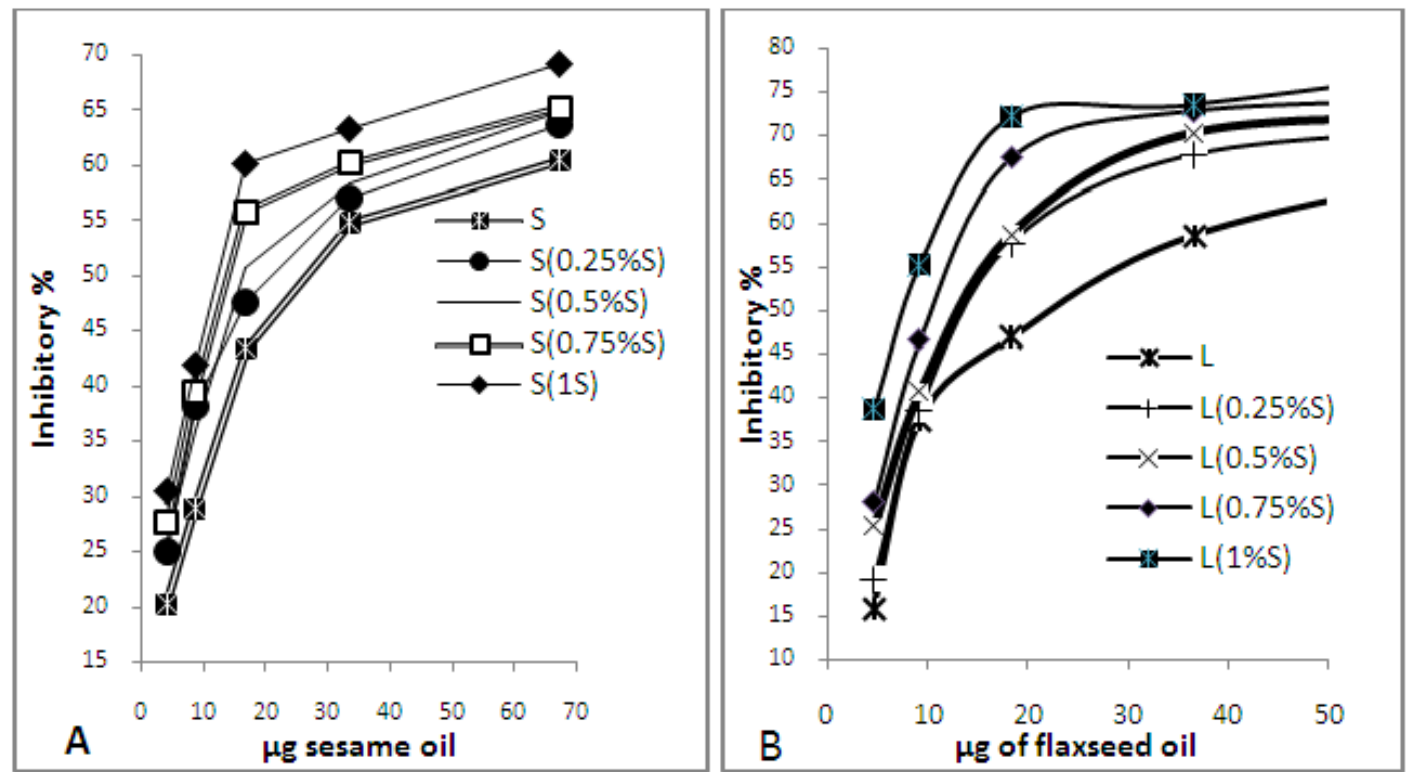

Figure 1 The antioxidant activity of Sesame (A), flaxseed (B) oils with different concentration of S. khuzistanica oil by DPPH method

According to our results, sesame oil has shown the better antimicrobial potency than that of flaxseed oil, while its antioxidant activity was lower than the flaxseed oil. The difference in antimicrobial and antioxidant activities of vegetable oils is related to their fatty acid profiles. Oleic acid, linoleic acid (unsaturated fatty acids) as the main components of sesame oil have shown the antimicrobia activity against Gram positive bacteria with MIC $0.01-0.1 \mathrm{mg} / \mathrm{ml}$ and also they have shown the synergistic effects with each other (Dilika et al., 2000). In fact the inhibition of $S$. aureus growth by vegetable oils particularly by sesame oil is related to oleic acid, linoleic acid and their synergistic effects between oleic acid and linoleic acid.

Furthermore, it has been reported, among different identified fatty acids in vegetable oils, palmitic acid and stearic acid has exhibited a weak antibacteria activity against $S$. aureus, while oleic acid and linoleic acid has shown high antibacterial activity against $S$. aureus. The antibacterial activity of oleic acid has been reported higher than that of linoleic acid (Zheng et al., 2005). In fact, the presence of higher antibacterial agents in sesame oil makes it as stronger antimicrobial agents. In total, identified unsaturated fatty acids in sesame oil were 
$83 \%$ of total fatty acids, while the corresponding amounts in flaxseed oil were $88 \%$. Identified saturated fatty acids were 15.1 and $10.6 \%$ for sesame and flaxseed oils, respectively. The interaction between saturated and unsaturated fatty acids makes flaxseed oils as a valuable antioxidant, although, the antioxidant potency of sesame oil was good. Other valuable finding of our study was traceability the essential oil in vegetable oils. In other word, carvacrol did not have any effects on chemical profiles of vegetable oils and the amount of carvacrol in vegetable oils was related to the inoculated essential oil into vegetable oil.

\section{CONCLUSION}

In conclusion, the use of Satureja khuzistanica essential oil in sesame and flaxseed oils as preservative and antioxidant agents can protect the vegetable oils from deterioration and also donates it other biological activity such as antiinflammatory effect and analgesic potency, without any changes in fatty acid profile of vegetable oils, whereas the use of this natural agent help to remove the adverse effects of chemical antioxidant and antimicrobial agents from the life of humans. The limitation of our study was no assessing the organoleptic effects of S. khuzistanica in vegetable oils for oral applications.

Acknowledgments: This study was supported by Biology Department, Faculty of Sciences, Boroujerd Branch, Islamic Azad University, Boroujerd, Iran.

\section{REFERENCES}

ADAMS, R. P. (2001). Identification of essential oil components by gas chromatography/mass spectroscopy.

AHMADVAND, H. (2014). Amelioration of altered antioxidant enzyme activity by Satureja khuzistanica essential oil in alloxan-induced diabetic rats. Chinese Journal of Natural Medicine, 12(9), 672-676. http://dx.doi.org/10.1016/s18755364(14)60102-3

AIT-OUAZZOU, A., ESPINA, L., GELAW, T. K., DE LAMO-CASTELLVI, S. PAGAN, R., \& GARCIA-GONZALO, D. (2013). New insights in mechanisms of bacterial inactivation by carvacrol. Journal of Applied Microbiology, 114(1), 173-185. http://dx.doi.org/10.1111/jam.12028

AKBARI-SHAHABI, S., ASSMAR, M., MASSIHA, A., GHAEMI, N., ISSAZADEH, K., \& SHOKRI-FASHTALI, S. (2014). Evaluation of antibacterial activity of Satureja khuzestanica J. essential oil against standard and isolated strains of Listeria monocytogenes. Zahedan Journal of Research in Medical Sciences, 16(10), 38-41.

ALUYOR, E. O., \& ORI-JESU, M. (2008). The use of antioxidants in vegetable oils-A review. African Journal of Biotechnology, 7(25), 4836-4842.

CACCIATORE, I., DI GIULIO, M., FORNASARI, E., DI STEFANO, A. CERASA, L. S., MARINELLI, L., . . CELLINI, L. (2015). Carvacrol codrugs: a new approach in the antimicrobial plan. PLoS One, 10(4), e0120937. http://dx.doi.org/10.1371/journal.pone.0120937

CHUECA, B., PAGAN, R., \& GARCIA-GONZALO, D. (2014). Oxygenated monoterpenes citral and carvacrol cause oxidative damage in Escherichia coli without the involvement of tricarboxylic acid cycle and Fenton reaction. International Journal Food Microbiology, 189, 126-131. http://dx.doi.org/10.1016/j.ijfoodmicro.2014.08.008

DAVIDSON, P. M., \& TAYLOR, T. M. (2007). Chemical preservatives and natural antimicrobial compounds. In Doyle $M$, Beuchat $L$ (ed), Food Microbiology.

DILIKA, F., BREMNER, P. D., \& MEYER, J. J. M. (2000). Antibacterial activity of linoleic and oleic acids isolated from Helichrysum pedunculatum: a plant used during circumcision rites. Fitoterapia, 71(4), 450-452. http://dx.doi.org/10.1016/S0367-326X(00)00150-7

ESMAEILI-MAHANI, S., EBRAHIMI, B., ABBASNEJAD, M., RASOULIAN B., \& SHEIBANI, V. (2015). Satureja khuzestanica prevents the development of morphine analgesic tolerance through suppression of spinal glial cell activation in rats. Journal of Natural Medicine, 69(2), 165-170. http://dx.doi.org/10.1007/s11418-013-0796-6

GHAZANFARI, G., MINAIE, B., YASA, N., NAKHAI, L. A., MOHAMMADIRAD, A., NIKFAR, S., . . . KHORASANI, R. (2006) Biochemical and histopathological evidences for beneficial effects of Satureja Khuzestanica Jamzad essential oil on the mouse model of inflammatory bowel diseases. Toxicology Mechanisms and Methods, 16(7), 365 372. http://dx.doi.org/10.1080/15376520600620125

GROMADZKA, J., \& WARDENCKI, W. (2011). Trends in Edible Vegetable Oils Analysis. Part A. Determination of Different Components of Edible Oils - a Review Polish Journal of Food and Nutrition Sciences 61(1), 33-43. http://dx.doi.org/10.2478/v10222-011-0002-z

LAMBERT, R., SKANDAMIS, P. N., COOTE, P. J., \& NYCHAS, G. J. (2001).

A study of the minimum inhibitory concentration and mode of action of oregano essential oil, thymol and carvacrol. Journal of Applied Microbiology, 91(3), 453 462. http://dx.doi.org/10.1046/j.1365-2672.2001.01428.x

MAHBOUBI, M., KAZEMPOUR, N., \& MAHBOUBI, A. (2014). The Efficacy of Essential Oils as Natural Preservatives in Vegetable Oil. Journal of Dietary Supplements, 11(4), 334-346. http://dx.doi.org/10.3109/19390211.2014.887603 MAHBOUBI, M., KAZEMPOUR, N., \& NAZAR, A. R. B. (2013). Tota phenolic, total flavonoids, antioxidant and antimicrobial activities of Scrophularia striata Boiss extracts. Jundishapur Journal of Natural Pharmaceutical Products $8(1), 15$.

OKPOKWASILI, G. C., \& MOLOKWU, C. N. (1996). Yeast and mould contaminants of vegetable oils. Bioresource Technology, 57(3), 245-249. http://dx.doi.org/10.1016/S0960-8524(96)00063-6

PARKE, D. V., \& LEWIS, D. F. V. (1992). Safety aspects of food preservatives. $\begin{array}{llll}\text { Food Additives \& Contaminants, } & 9(5), & 561-577 .\end{array}$

http://dx.doi.org/10.1080/02652039209374110

Pharmacopoeia, B. (2015a). Medicines Commission. Appendix XN V324, London: HM Stationery Office.

Pharmacopoeia, B. (2015b). Medicines Commission. Volum IV-388, London: HM Stationery Office.

SABERI, A., SEPEHRIB, G., ESMAEILI-MAHANI, S., RASOULIAN, B. SHEIBANI, V., ESMAEILPOUR, K., . . . ABBASLOO, E. (2013). Satureja khuzestanica extract elicits antinociceptive activity in several model of pain in rats. Journal of Applied Sciences, 13(5), 729.

SADEGHI-NEJAD, B., SHIRAVI, F., GHANBARI, S., ALINEJADI, M., \& ZARRIN, M. (2010). Antifungal activity of Satureja khuzestanica (Jamzad) leaves extracts. Jundishapur Journal of Microbiology, 3, 36-40.

SAIDI, M. (2014). Antioxidant Activities and Chemical Composition of Essential Oils from Satureja khuzestanica, Oliveria decumbens and Thymus daenensis Journal of Essential Oil Bearing Plants, 17(3), 513-521. http://dx.doi.org/10.1080/0972060x.2014.901607

SIAVASH SAEI-DEHKORDI, S., FALLAH, A. A., HEIDARI-NASIRABADI M., \& MORADI, M. (2012). Chemical composition, antioxidative capacity and interactive antimicrobial potency of Satureja khuzestanica Jamzad essential oil and antimicrobial agents against selected food-related microorganisms International Journal of Food Science \& Technology, 47(8), 1579-1585 http://dx.doi.org/10.1111/j.1365-2621.2012.03006.x

SMITH-PALMER, A., STEWART, J., \& FYFE, L. (2001). The potential application of plant essential oils as natural food preservatives in soft cheese Food Microbiology, 18(4), 463-470. http://dx.doi.org/10.1006/fmic.2001.0415

SUTTON, S. V., \& PORTER, D. (2002). Development of the antimicrobial effectiveness test as USP chapter<51>. PDA Journal of Pharmaceutical Science and Technology, 56(6), 300-311.

ZARRIN, M., AMIRRAJAB, N., \& SADEGHI-NEJAD, B. (2010). In vitro antifungal activity of Satureja khuzestanica Jamzad against Cryptococcus neoformans. Pakistan Journal of Medical Science, 26(4), 880.

ZHENG, C. J., YOO, J.-S., LEE, T.-G., CHO, H.-Y., KIM, Y.-H., \& KIM, W.-G (2005). Fatty acid synthesis is a target for antibacterial activity of unsaturated $\begin{array}{llll}\text { fatty acids. } & \text { FEBS } & \text { Letters, }\end{array}$ http://dx.doi.org/10.1016/j.febslet.2005.08.028 